
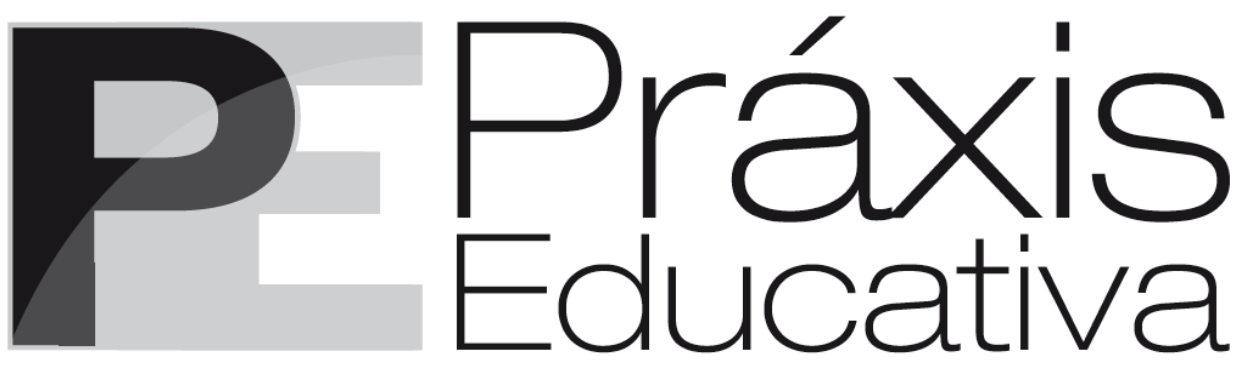

ISSN 1809-4031

elSSN 1809-4309

https://doi.org/10.5212/PraxEduc.v.16.15630.020

\title{
Pensamento educacional brasileiro em Portugal: Paulo Freire na formação de professores e em publicações acadêmico-científicas
}

\section{Brazilian educational thought in Portugal: Paulo Freire in teacher education and scientific publications}

\section{Pensamiento educativo brasileño en Portugal: Paulo Freire en la formación del professorado y en las publicaciones académico-científicas}

\author{
Maria Edith Romano Siems* \\ (iD) https://orcid.org/0000-0001-5527-0065 \\ Maria João Mogarro** \\ (D) https://orcid.org/0000-0002-5841-9280
}

\begin{abstract}
Resumo: O estudo buscou compreender a presença do pensamento educacional brasileiro em Portugal em cursos de formação de professores e na produção científica de periódicos educacionais. Adotou-se como procedimentos metodológicos a pesquisa documental, analisando as unidades curriculares de cursos de licenciaturas e mestrados em ensino de universidades portuguesas, bem como artigos científicos publicados no período de 2006 a 2019 em periódicos vinculados também a universidades portuguesas. Tomaram-se como referenciais teóricos os estudos de Roger Chartier sobre circulação e apropriação de modelos culturais e saberes pedagógicos e os de Pierre Bourdieu ao discutir-se acerca das noções de campo cultural e processos de interpretação gerados na relação com os poderes e as influências exteriores. Os resultados apontaram a significativa presença da produção bibliográfica de Paulo Freire e a apropriação de suas concepções filosóficas, sociológicas e pedagógicas no contexto português.

Palavras-chave: Paulo Freire. Formação de professores. Circulação de ideias pedagógicas.
\end{abstract}

Abstract: The study presented here sought to understand the presence of Brazilian educational thought in Portugal in teacher education courses and in the scientific production of educational journals. We adopted documentary research as methodological procedures, analyzing the curricular units of undergraduate and master's degrees in teaching at Portuguese universities, as well as scientific articles published in the period from 2006 to 2019 in periodicals also linked to Portuguese universities. We take as theoretical references the studies of Roger Chartier on circulation and appropriation of cultural models and pedagogical knowledge

\footnotetext{
* Doutora em Educação Especial pela Universidade Federal de São Carlos (UFSCar). Professora do Centro de Educação da Universidade Federal de Roraima. E-mail: <edithromanos@hotmail.com>.

** Doutora em Ciências da Educação pela Universidade de Lisboa (Portugal). Professora do Instituto de Educação da Universidade de Lisboa. E-mail: <mjmogarro@ie.ulisboa.pt>.
} 
and the studies of Pierre Bourdieu when discussing the notions of cultural production field and the interpretation processes generated in the relationship with external powers and influences. The results point to the significant presence of Paulo Freire's bibliographic production and appropriation of his philosophical, sociological and pedagogical conceptions in the Portuguese context.

Keywords: Paulo Freire. Teacher education. Circulation of pedagogical ideas.

Resumen: El estudio buscó comprender la presencia del pensamiento educativo brasileño en Portugal en los cursos de formación docente y en la producción científica de revistas educativas. Se adoptó como procedimiento metodológico la investigación documental, analizando las unidades curriculares de los grados y másteres en docencia en las universidades portuguesas, así como los artículos científicos publicados en el período de 2006 a 2019 en revistas también vinculadas a las universidades portuguesas. Los estudios de Roger Chartier sobre la circulación y apropriación de modelos culturales y saberes pedagógicos y los de Pierre Bourdieu fueron discutidos como referentes teóricos al discutir las nociones de campo cultural y procesos de interpretación generados en la relación con poderes e influencias externas. Los resultados mostraron la presencia significativa de la producción bibliográfica de Paulo Freire y la apropriación de sus concepciones filosóficas, sociológicas y pedagógicas en el contexto portugués.

Palabras clave: Paulo Freire. Formación de profesores. Circulación de ideas pedagógicas.

\section{Introdução}

O presente artigo apresenta os resultados de um estudo que teve por objetivo compreender a presença do pensamento educacional brasileiro na formação de professores e na produção de conhecimento acadêmico-científico do campo da educação em Portugal.

Inicialmente, projetou-se analisar os conteúdos e os autores indicados como referências nos programas das unidades curriculares oferecidas em cursos de licenciatura em ciências da educação ou em mestrados em ensino de universidades portuguesas. Nas unidades curriculares analisadas, observou-se uma reduzida e dispersa referência a alguns autores brasileiros, sem regularidade ou afiliação teórica que se destacasse.

No entanto, entre os autores brasileiros citados nos programas constatou-se a presença constante e sistemática de obras de Paulo Freire. O estudo analisou a produção científica portuguesa do campo da educação de textos que apresentassem referências diretas a Paulo Freire ou a conceitos por esse educador desenvolvidos, entendendo serem publicações tanto resultado de processos formativos iniciais de professores quanto subsídios à formação permanente desses profissionais.

As referências encontradas relacionam-se ao trabalho de Paulo Freire na alfabetização de adultos, mas também, e principalmente, trazem apontamentos em relação à filosofia educativa que subjaz a seu pensamento no conjunto das pedagogias críticas e em campos de saber que se articulam às ciências da educação, como a sociologia, a história, a cultura e estudos linguísticos.

O entendimento aqui apresentado, pautado na perspectiva histórico-cultural de compreensão da realidade, é o de que as ideias e concepções pedagógicas surgem e desenvolvemse como resposta a demandas educativas concretas em determinado contexto social e cultural. Correlacionam-se a um tempo histórico, envolvendo um grupo sociocultural específico e uma demanda coletiva de formação, o que não elimina o fato de que sejam potencialmente válidas também para outras sociedades e culturas. Nesse sentido, a pesquisa insere-se também no conjunto dos estudos que buscam compreender como se dá a circulação do pensamento educacional entre diferentes grupos sociais e culturais, em contextos nacionais diferenciados.

O artigo apoia-se nos estudos de Roger Chartier e Pierre Bourdieu, autores que auxiliam na compreensão dos processos de circulação de modelos culturais e de como se materializam a 
circulação e a apropriação de saberes pedagógicos - no caso em tela, o pensamento educacional brasileiro no contexto português. Trata-se de pesquisa de abordagem metodológica qualitativa, com apresentação descritiva dos dados encontrados.

\section{Educação e formação de professores no Brasil e em Portugal}

As interfaces e os pontos convergentes entre a história da educação brasileira e a história da educação portuguesa são intensos e significativos, considerando esse entrelaçamento a partir do período colonial e estendendo-se até os dias atuais, quando, mesmo diante da condição de tratarse de nações independentes, prosseguem os laços de interlocução e o intercâmbio entre intelectuais e pesquisadores brasileiros e portugueses.

Várias similaridades na trajetória histórica dos dois países os aproximam, a exemplo do fato de que tanto Portugal quanto Brasil vivenciaram governos totalitários nas décadas de 1960 e 1970. Além disso, ao longo dos anos de 1970 e 1980, ambos enfrentaram intensos desafios para ampliar o acesso de suas crianças e jovens à educação escolar básica, chegando, em vários momentos, a apresentar índices semelhantes de analfabetismo de jovens e adultos.

Ao longo dos anos de 1990 e início dos anos 2000, também ambos os países foram impactados "pelo movimento internacional das reformas educacionais", com destaque para a "proposta pedagógica do professor reflexivo" (GABARDO, 2007, p. 279-280). A discussão sobre as perspectivas de formação de professores foi, no Brasil, pautada em muitos momentos por publicações de autores portugueses, dos quais se destacam aquelas organizadas por Antonio Nóvoa e Isabel Alarcão, entre outros autores de origem portuguesa.

$\mathrm{Na}$ atualidade, embora trilhando caminhos diversos, com Portugal em trajetória de melhoria de seus índices aferidos em processos de avaliação educacional e o Brasil vivendo incontáveis retrocessos, Brasil e Portugal se embatem com o desafio de universalizar uma educação básica de qualidade à sua população com a tendência de creditar à formação de professores parte expressiva da responsabilidade quanto ao fracasso ou sucesso no alcance desse objetivo.

Nas últimas décadas, a aplicação de testes internacionais estandardizados, como o Programa Internacional de Avaliação de Estudantes (PISA), consolidou-se tanto na Europa quanto na América Latina. No Brasil, foram implantados exames nacionais para os diferentes níveis e efetivado um acompanhamento dos resultados de testes internacionais, como é o caso do referido PISA. Importante mencionar que, nas análises que se reportam ao desempenho dos estudantes brasileiros nessa avaliação, os referenciais encontrados são preocupantes, como apontam Sassaki et al. (2018).

Nesse contexto, avaliações sistemáticas, em sua aplicação ampla e regular, revelando baixos índices de desempenho dos estudantes brasileiros repercutem na mídia, alimentada por manifestações de técnicos e gestores dos sistemas educacionais, que creditam quase exclusivamente à formação de professores a responsabilidade pelos frágeis resultados obtidos pelos estudantes, posição com a qual não se concorda por entender-se que vários são os fatores que podem intervir na qualidade do desenvolvimento da aprendizagem.

Em contraste com o percurso brasileiro, a experiência portuguesa registra no PISA a melhoria dos índices de desempenho dos estudantes, com destaque nos avanços vivenciados nos últimos anos em suas escolas, constatados em avaliações de larga escala e reconhecidos até mesmo no plano da mídia internacional (PEZZONI, 2018). 
Entre os aspectos ressaltados como fatores que contribuíram para esse crescimento, temse em perspectiva a formação de professores. Nas análises destaca-se que "os professores em Portugal são melhor formados e selecionados hoje do que há 15 anos - entre os docentes do $3^{\circ}$ ciclo e secundário, [...] a formação pedagógica específica aumentou 48\% entre 2003 e 2015" (PEZZONI, 2018).

Embora outros fatores sejam considerados intervenientes no alcance desses resultados, há uma ênfase na contribuição da reformulação das políticas de formação de professores em Portugal, a partir do decreto-lei n. 43, de 22 de fevereiro de 2007, que, no entendimento de Pintassilgo e Oliveira (2013, p. 39-40), contribuiu para "permitir, a prazo, a valorização do estatuto profissional, aspeto particularmente crítico ao longo da história da profissão".

Paralelamente, no Brasil, os discursos críticos relativos à estruturação dos cursos de formação foram tomados por manifestações que condenam os currículos atuais adotados, sob a acusação de serem excessivamente teóricos, com foco reduzido nas práticas pedagógicas (GATTI, 2010, p. 1.375). Interessante observar que, no âmbito das discussões sobre práticas, em muitos momentos esta é destacada como se fosse possível dissociá-la dos "discursos que as prescrevem ou as proscrevem, as descrevem ou as organizam" (CHARTIER, 2013a, p. 26).

Ao percurso trilhado por órgãos do governo federal brasileiro de revisar as políticas de formação de professores, com precária observação do conhecimento produzido pelos profissionais e pesquisadores da área, têm sido registradas frequentes manifestações de dirigentes e gestores educacionais atribuindo a pensadores e pesquisadores brasileiros de amplo reconhecimento internacional e a suas teorias educacionais a responsabilidade pelos problemas vivenciados na formação de professores e, consequentemente, no baixo desempenho apresentado pelos estudantes da educação básica.

Dessa forma, pretende-se compreender se na formação de professores e na produção do conhecimento científico no campo da educação em Portugal encontra-se a influência de concepções educacionais produzidas por pesquisadores/educadores brasileiros. Nesse intuito, apresentam-se as seguintes questões: Nas unidades curriculares praticadas nos cursos de formação de professores em Portugal, encontram-se presentes ideias pedagógicas, teorias e/ou conceitos desenvolvidos por pensadores e pesquisadores brasileiros? Na produção acadêmica que se difunde em periódicos científicos portugueses, há a presença de elementos do pensamento educacional desenvolvido no Brasil, que, por sua vez, vem sendo responsabilizado pelos resultados insatisfatórios obtidos nas avaliações dos estudantes e dos sistemas educativos por parte dos atuais líderes políticos brasileiros?

Considerando tais questões e a compreensão de que a formação de professores e a construção de conhecimentos em educação são condições básicas para o desenvolvimento educativo local, a investigação vincula-se à presença do pensamento educacional brasileiro em Portugal nos currículos de formação de professores e nos periódicos que tomam como foco e escopo a educação.

\section{Fundamentos Teórico Metodológicos}

\section{Abordagem metodológica}

Como aponta Saviani (2010), método de estudo é um movimento que tem seu ponto de partida e de chegada na vida, nas práticas sociais. Vista como um ponto de partida, a vida apresenta- 
se como um fato natural, descontextualizado, e para que se possa retomar a vida em sua complexidade é necessário que se conheçam sua historicidade e os múltiplos fatores que foram determinando as práticas sociais de um coletivo. Nesse sentido, este estudo se desdobra em um movimento mais amplo, com um olhar sobre a identificação do processo histórico por meio do qual o pensamento educacional brasileiro inseriu-se em Portugal. No recorte apresentado, entretanto, enfatizam-se os achados referentes ao processo de circulação das ideias pedagógicas do Brasil para Portugal e suas apropriações na produção de conhecimento e na formação de professores portugueses.

Ao procurar conhecer os programas de formação de professores vigentes em Portugal e, no interior deles, a presença de influências de pensadores e pesquisadores brasileiros, entende-se essa formação como um espaço de "vida", assim como as instituições e a produção científica que se pretende compreender.

O interesse aqui não se limita a identificar a presença do pensamento brasileiro na formação de professores em Portugal e na produção do conhecimento educacional expresso nas publicações de periódicos especializados, mas compreendê-lo em movimento, observando o contexto histórico, cultural e social que levou à sua constituição e a forma como determinados saberes foram aí apropriados. O conceito de apropriação aqui utilizado é o de Chartier (2013a, p. 26), "entendida ao mesmo tempo como controle e uso, como vontade de possessão exclusiva pelas autoridades e como invenção pelos consumidores comuns". Pauta-se ainda em Chartier (1994; 2013b) no tocante às reflexões sobre os processos de produção de livros e concepções de cultura e representações sociais.

Toma-se também como referencial teórico para embasar os processos reflexivos e de análise os trabalhos de Pierre Bourdieu (1991; 1996), com discussões relativas às noções de campo de produção cultural evidenciando como, em seu interior, diferentes indivíduos, enquanto autores, interpretam diferentemente ideias específicas de outros mediante a produção de leituras próprias (traduções, refrações), assim como se debruçam sobre seus contextos de produção estabelecendo relações com as diversas instâncias de saber, poder e influências exteriores (MOGARRO, 2006).

Os autores brasileiros citados nas bibliografias dos programas dos cursos de formação de professores e, pincipalmente, aqueles referenciados nos artigos científicos publicados em Portugal (nos quais Paulo Freire se destaca como paradigma conceptual) expressam esse processo de interpretação, de leituras próprias realizadas pelos pensadores portugueses (e de outras nacionalidades) que revelam em seus textos as formas como leram Freire e como mobilizaram suas ideias para um discurso próprio, que é individual. Esses pensadores constituem o conjunto de autores dos artigos analisados, que, em um contexto de liberdade e diálogo intenso que caracteriza o campo de produção científica, os elaboraram com elevado grau de autonomia e responsabilidade. A centralidade de Paulo Freire reflete a importância do seu pensamento, a circulação intensa que sua obra alcançou entre Brasil, Portugal e outras geografias do mundo e, principalmente, a apropriação do seu pensamento, com o qual muitos desses autores se identificam de modo tão articulado.

\section{Procedimentos metodológicos}

No estudo realizado, partiu-se de bases documentais e analisaram-se os programas das unidades curriculares de cursos de formação de professores disponibilizados em páginas eletrônicas, mediante o mapeamento da oferta de disciplinas em cursos de licenciatura em Ciências da Educação e mestrados em ensino de disciplinas específicas ou em Ciências da Educação das universidades de Lisboa, Porto, Coimbra e Évora, escolhidas por sua presença estratégica em 
diferentes regiões (norte, centro e sul do país) e por sua relevância na produção científica portuguesa.

Ao verificar o uso de referenciais bibliográficos de autores brasileiros nessas unidades curriculares, identificou-se uma pulverização de citações a autores que se inserem nos diferentes campos que fundamentam as Ciências da Educação, como as seguintes presenças demonstram: Boto (2006), Gondra (2002) e Vidal (2006) na História da Educação; Oliveira (1997) na Psicologia da Educação; Laraia (1986) na Antropologia da Educação; Mainardes (2006), Candau (2008) e Meksenas (2002) em textos que transitam entre a Filosofia da Educação e Políticas Educacionais; Pimenta (2006) na Didática; Silva (2005) na discussão relativa a Teorias do Currículo e Ana Mae Barbosa na Arte Educação. Em todos esses casos, há a predominância da referenciação de publicações em formato livro - 24 dentro de um total de 27 referências -, reafirmando a importância que esse tipo de produção ainda tem para a circulação de ideias, apesar do forte crescimento das condições de acesso a textos em arquivos digitais.

Foi possível observar que, além das citações aos autores mencionados, as demais referências eram de obras de Freire (1971, 1972, 1975a, 1975b, 1994, 1996 e 2000a). Há uma presença marcante das publicações clássicas, entendidas como instauradoras de seu pensamento, tais como Pedagogia do oprimido, livro referenciado cinco vezes em edições portuguesas, e textos como Educaşão como prática de liberdade e Extensão on comunicaşão, referenciados uma vez cada em edições de editoras brasileiras. Da série de publicações mais recentes de Freire, destaca-se Pedagogia da autonomia: saberes necessários à prática educativa, referenciado em quatro disciplinas, além de textos como Cartas à Cristina e $A$ importância do ato de ler.

A referenciação a Freire ocorre em diferentes disciplinas, que vão desde aquelas que se relacionam à educação e formação de adultos àquelas que tratam da organização e administração educacional e filosofia da educação. No caso das unidades curriculares específicas de educação e formação de adultos, Paulo Freire está presente nas indicações bibliográficas das unidades curriculares em todas as instituições, mostrando quanto o pensamento freiriano é indissociável do "campo de práticas educativas; campo de práticas de investigação e campo de práticas discursivas" (MACHADO; BARROS, 2020, p. 94), que é a educação de jovens e adultos.

Com base nesses dados em que se verifica claramente a posição de destaque ocupada pelo educador Paulo Freire nos programas dos cursos de formação de professores em universidades portuguesas, coloca-se a seguinte questão: Se nos processos formativos iniciais de professores há tão expressiva presença do pensamento filosófico, sociológico e educacional de Paulo Freire, de que forma essa manifestação se estende na produção científica da área?

Assim, partiu-se para um processo de revisão em periódicos portugueses que têm a educação como foco principal, ou um dos mais destacados. Optou-se por assumir como campo de pesquisa periódicos relevantes e vinculados a universidades sediadas em Lisboa, Coimbra, Porto e Minho, delimitando um período entre os anos de 2006 e 2019. Essa delimitação temporal justificase pelo fato de que a maioria dos periódicos não oferece acesso em formato digital a arquivos que antecedem a esse período, o que possivelmente criaria dificuldades no mapeamento de acervos em arquivos impressos, intransponíveis dentro dos limites materiais de realização deste trabalho.

Considerou-se um total de oito periódicos, tendo-se identificado quase uma centena de artigos que foram analisados em diferentes perspectivas, com conclusões e resultados que serão apresentados mais adiante. Dessa forma, o cerne do estudo que se apresenta neste artigo configurou-se como uma revisão de literatura sobre a presença da obra de Paulo Freire na produção das Ciências Sociais, com ênfase no campo educacional, em Portugal. 
Como critérios para a seleção dos periódicos a serem analisados, consideraram-se sua vinculação a universidades com tradição na área de formação de professores e a regularidade de publicações, que se destacam, em alguns casos também, pelo desempenho e indexação em bases de avaliação internacional. Verificou-se ainda a indexação desses periódicos e sua avaliação no Qualis Capes 2016.

Dentro desses critérios, selecionaram-se para o estudo os periódicos descritos no Quadro 1.

Quadro 1 - Periódicos utilizados como referencial de pesquisa, por vinculação, periodicidade e impacto acadêmico

\begin{tabular}{|c|c|c|c|c|}
\hline & Periódico & Vinculação & Periodicidade & Indexação \\
\hline 1 & $\begin{array}{l}\text { Educação Sociedade } \\
\text { \& Culturas }\end{array}$ & $\begin{array}{l}\text { Centro de Investigação e Intervenção } \\
\text { Educativas, Universidade do Porto. }\end{array}$ & $\begin{array}{l}\text { Desde } 1994 \\
\text { Semestral }\end{array}$ & $\begin{array}{l}\text { EBSCO, ERIH, Latindex } \\
\text { e AERES. } \\
\text { Qualis Capes B1. }\end{array}$ \\
\hline 2 & $\begin{array}{l}\text { Revista Lusófona } \\
\text { de Educação }\end{array}$ & $\begin{array}{l}\text { Centro de Estudos Interdisciplinares em } \\
\text { Educação e Desenvolvimento, Instituto } \\
\text { de Educação, Universidade Lusófona. }\end{array}$ & $\begin{array}{l}\text { Desde } 2013 \\
\text { Quadrimestral }\end{array}$ & $\begin{array}{l}\text { Scopus, SciElo e } \\
\text { Redalyc. } \\
\text { Qualis Capes A1. }\end{array}$ \\
\hline 3 & $\begin{array}{l}\text { Revista Portuguesa } \\
\text { de Educação }\end{array}$ & Universidade do Minho. & $\begin{array}{l}\text { Desde } 1988 \\
\text { Semestral }\end{array}$ & $\begin{array}{l}\text { SciElo e Scopus. } \\
\text { Qualis Capes A1. }\end{array}$ \\
\hline 4 & $\begin{array}{l}\text { Revista Portuguesa } \\
\text { de Investigação } \\
\text { Educacional }\end{array}$ & $\begin{array}{l}\text { Faculdade de Educação e Psicologia, } \\
\text { Universidade Católica Portuguesa (Braga, } \\
\text { Lisboa, Porto, Viseu). }\end{array}$ & $\begin{array}{l}\text { Desde } 2002 \\
\text { Anual }\end{array}$ & $\begin{array}{l}\text { Latindex e REDIB. } \\
\text { Qualis Capes B3. }\end{array}$ \\
\hline 5 & $\begin{array}{l}\text { Revista Portuguesa } \\
\text { de Pedagogia }\end{array}$ & $\begin{array}{l}\text { Faculdade de Psicologia e de Ciências da } \\
\text { Educação, Universidade de Coimbra. }\end{array}$ & $\begin{array}{l}\text { Desde } 1960 \\
\text { Semestral }\end{array}$ & $\begin{array}{l}\text { Eriphlus e Livre. } \\
\text { Qualis Capes B3. }\end{array}$ \\
\hline 6 & $\begin{array}{l}\text { Sisyphus: Journal } \\
\text { of Education }\end{array}$ & $\begin{array}{l}\text { Instituto de Educação, Universidade de } \\
\text { Lisboa. }\end{array}$ & $\begin{array}{l}\text { Desde } 2013 \\
\text { Quadrimestral }\end{array}$ & $\begin{array}{l}\text { Erihplus, Latindex e } \\
\text { Livre. } \\
\text { Qualis Capes C. }\end{array}$ \\
\hline 7 & $\begin{array}{l}\text { Sísifo - Revista de } \\
\text { Ciências da } \\
\text { Educação }\end{array}$ & $\begin{array}{l}\text { Departamento de Ciências da Educação, } \\
\text { Faculdade de Psicologia e Ciências da } \\
\text { Educação, Universidade de Lisboa. }\end{array}$ & 2006 a 2010 & Encerrada em 2010. \\
\hline 8 & $\begin{array}{l}\text { Revista de } \\
\text { Educação }\end{array}$ & $\begin{array}{l}\text { Departamento de Educação da } \\
\text { Faculdade de Ciências, Universidade de } \\
\text { Lisboa. }\end{array}$ & 1986 a 2011 & Encerrada em 2011. \\
\hline
\end{tabular}

Fonte: Banco de dados da pesquisa. Elaboração das autoras.

As publicações da Sísifo - Revista de Ciências da Educação e da Revista de Educação, indicadas como já encerradas, foram mantidas no estudo por compreenderem diferentes períodos de publicações que têm vínculos com o Instituto de Educação da Universidade de Lisboa, que passaram por fases sucessivas, com descontinuidades, mas mantidas por constituírem a sequência de um relevante projeto editorial. Assim, destaca-se que a Revista de Educação é caracterizada em sua página eletrônica como um "meio de divulgação da investigação no campo da educação e um instrumento de trabalho útil de reflexão indispensável ao desenvolvimento da profissionalidade dos docentes nos diversos níveis de ensino", e a Sísifo, por sua vez, é descrita como destinada a "contribuir para a internacionalização da produção científica em Ciências da Educação, ajudando a fomentar intercâmbios que viabilizassem, sustentassem e tornassem visíveis redes e projetos que 
ultrapassassem fronteiras nacionais". Sublinhe-se que essas duas revistas são antecessoras da atual Sisyphus - Journal of Education, assim como os dois departamentos que garantiram a sua edição foram reconfigurados, saindo das faculdades de origem e sustentando ambos a criação do atual Instituto de Educação da Universidade de Lisboa.

No conjunto das publicações consideradas no corpus de pesquisa, duas ocorrências específicas merecem destaque: excedendo o limite temporal de análise proposto, na revista Educação, Sociedade \& Culturas, da Universidade do Porto, foram encontrados dois números especiais dedicados a Paulo Freire, a edição de número 10, do ano de 1998, e a de número 23, do ano de 2005. Nessas edições especiais dedicadas a um pensador brasileiro, destacam-se trabalhos produzidos por autores das mais diversas nacionalidades e focos de atenção, mas optou-se por não considerá-los por encontrarem-se fora do lapso temporal a que se propõe o estudo aqui.

Outra situação que merece ser observada refere-se à Revista Lusófona de Educação, que também apresenta números especialmente dedicados a Paulo Freire e certa regularidade na publicação de artigos que o tomam como foco. Entretanto, na análise do material publicado, é possível constatar que em sua quase totalidade são artigos produzidos por pesquisadores brasileiros, tradicionais nos estudos relativos a Freire no Brasil. Essa característica, de certa forma, acarretaria distorções do objetivo empreendido, que é o de compreender as apropriações do pensamento freiriano em contexto português, razão pela qual, para os fins da pesquisa, optou-se pela não utilização desses artigos nas análises.

Em números, o corpus de estudo constituiu-se de 97 artigos que mencionam Paulo Freire em suas referências. Embora a metodologia não se configure como de natureza quantitativa, identificaram-se algumas regularidades que parecem relevantes no que se refere aos direcionadores de análise, como a regularidade de publicações ao longo do período em estudo, conforme apresentado no Gráfico 1.

Gráfico 1 - Número de artigos que fazem referências a Paulo Freire, por ano de publicação

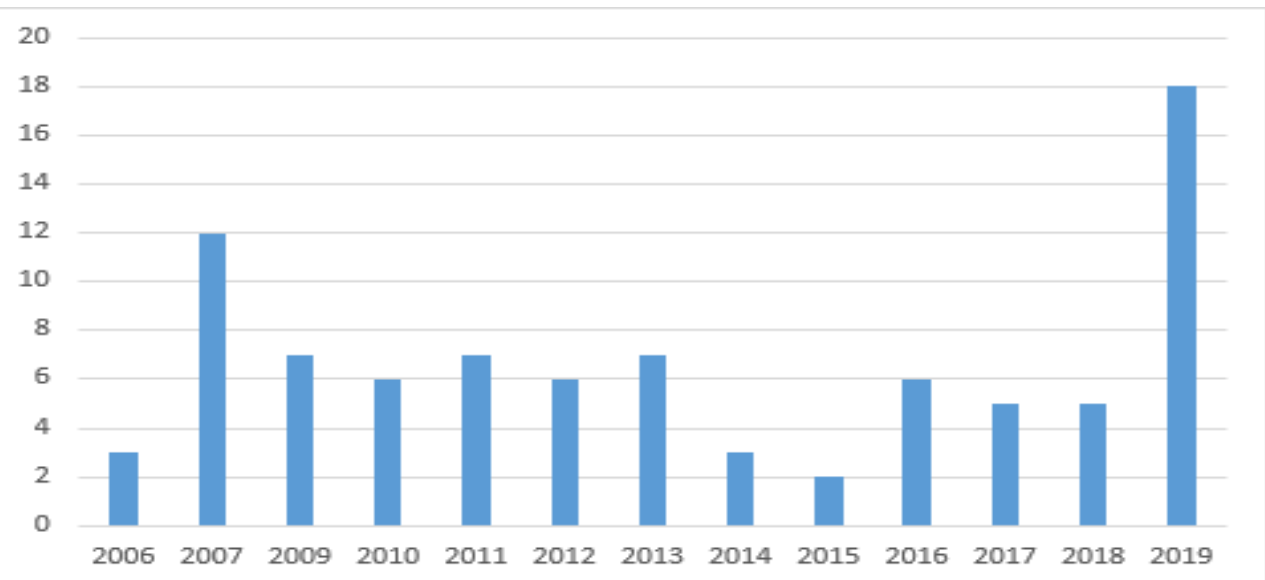

Fonte: Banco de dados da pesquisa. Elaboração das autoras.

No Gráfico 1, observa-se uma regularidade no volume numérico de publicações ao longo de 13 anos. Dois anos apresentam expressivo destaque, 2007 e 2019. Nesses dois momentos, entende-se a possibilidade de correlação com fatores externos: no primeiro caso pela realização, nos anos de 2006 e 2007, de eventos científicos envolvendo a pedagogia freiriana; da mesma forma em 2018, quando o Instituto Paulo Freire em Portugal realizou, em parceria com a Faculdade de Psicologia e de Ciências da Educação da Universidade do Porto, evento comemorativo aos cinquenta anos de finalização da escrita do mais aclamado livro de Freire em Portugal, Pedagogia do oprimido. É também 2019 o ano em que fortes ataques ao educador brasileiro são feitos pelos então 
dirigentes eleitos ao governo do Brasil e suas equipes de "especialistas", alçados à condição de ministros e assessores, o que certamente traz a possibilidade de reação de autores da área, retomando as obras do consagrado educador.

No que diz respeito à vinculação dos pesquisadores que publicaram artigos mencionando Paulo Freire como referência, encontra-se também uma diversidade de localizações que são demarcadores relevantes do alcance dessa produção. De maneira geral, entre os 97 artigos considerados, encontram-se 25 ou pouco mais de um quarto deles produzidos por pesquisadores vinculados a universidades brasileiras, mas o destaque que parece de maior relevância refere-se à diversidade de localização geográfica dos demais autores, a saber: 56 deles produzidos por autores portugueses distribuídos nas mais diversas regiões de Portugal, $4 \mathrm{em}$ parcerias de autores brasileiros com portugueses e os demais artigos são escritos por pesquisadores com vinculações em universidades francesas (3), espanholas (3), inglesas (2), canadenses (2), chinesa (1) e cubana (1).

No tocante à forma como se veicula a presença de Paulo Freire na referenciação dos textos, aspecto de grande relevância para se compreender como ocorrem a apropriação e a circulação do pensamento freiriano na produção científica e educacional portuguesa, estabeleceram-se algumas categorias, das quais se destacam: a) o contexto da produção, considerando se o artigo produzido relaciona-se a um processo desenvolvido em projetos de pesquisa como parte de uma investigação empírica, relato de experiência ou ensaio teórico, por exemplo; b) na sequência, analisou-se a área de prevalência do artigo, entendendo "área" como a disciplina de vinculação, o nível ou modalidade de ensino à qual o estudo apresentado no artigo se refere; c) verificou-se, ainda, quais os conceitos freirianos que se destacam; títulos da produção freiriana com maior recorrência; qual a posição da citação freiriana no texto e, finalmente, d) com quais autores ou campos de conhecimento a produção freiriana é correlacionada.

\section{Presença do pensamento de Paulo Freire em artigos publicados em periódicos portugueses da área da educação no período de 2006 a 2019}

Embora a intenção do estudo em tela seja constituir-se essencialmente em pesquisa de metodologia qualitativa, nas análises foi possível depreender aspectos quantitativos que oferecem elementos relevantes para a compreensão das regularidades, dos impactos e das prevalências em cada uma das categorias que se projetou analisar. A intenção é de, com base nos indícios encontrados quantitativamente, compreender os aspectos qualitativos fundamentais presentes nesse universo de produção científica.

\section{Contexto de produção e áreas de conhecimento enfatizadas}

Em relação ao contexto de produção dos artigos em análise que foram alvo de atenção por apresentarem referências a Paulo Freire, foi possível observar diferentes modalidades de trabalho, conforme evidencia o Gráfico 2. 
Pensamento educacional brasileiro em Portugal: Paulo Freire na formação de professores...

Gráfico 2 - Artigos analisados com base na verificação do contexto acadêmico de produção

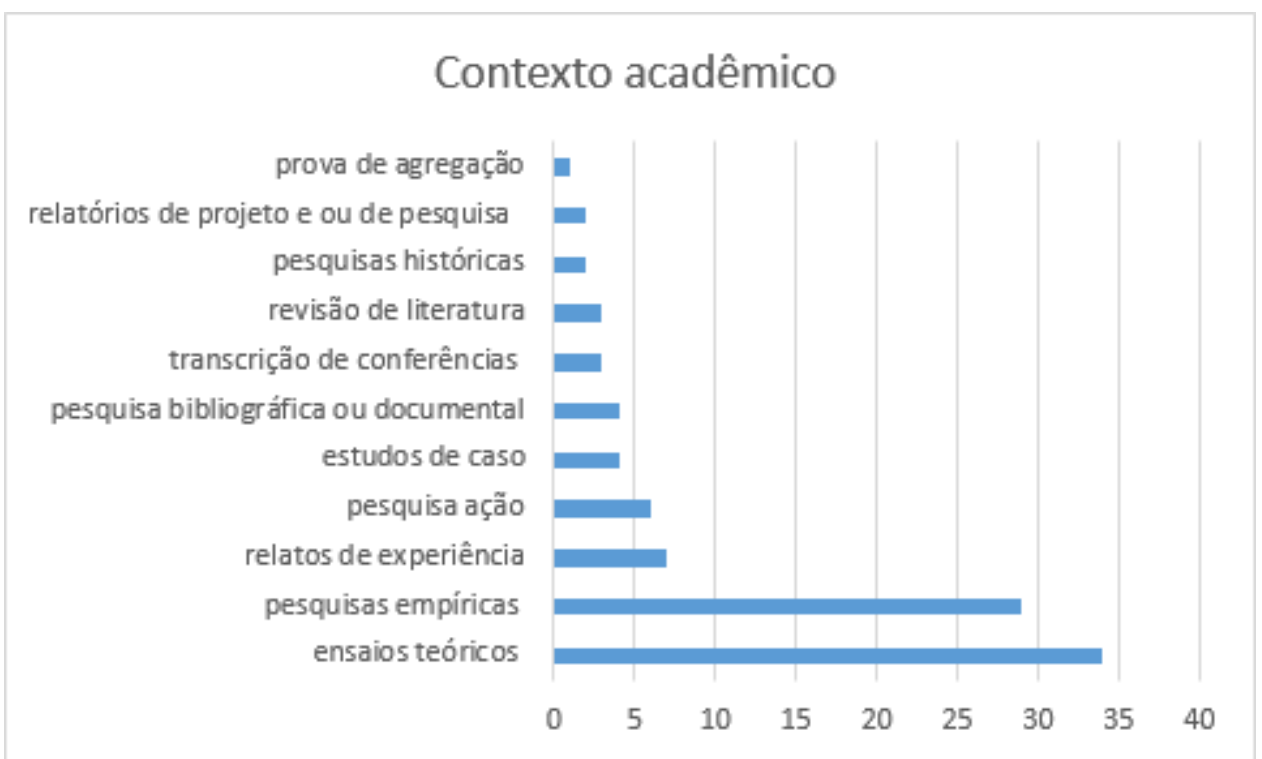

Fonte: Banco de dados da pesquisa. Elaboração das autoras.

$\mathrm{Na}$ análise desses dados, verifica-se uma prevalência de trabalhos no formato de ensaios teóricos (36), seguidos de perto por artigos que apresentam resultados de pesquisas empíricas sem maiores enquadramentos descritos (29). Encontra-se ainda expressivo volume de relatos de experiência (7) e de investigações na forma de pesquisa-ação (6), estudos de caso (4) e pesquisa bibliográfica ou documental (4). Em menor quantidade encontram-se textos que se referem à transcrição de conferências (3), revisão de literatura (3), pesquisas históricas (2), relatórios de projeto e ou de pesquisa (2) e uma prova de agregação.

No tocante à área de conhecimento, contrariando as concepções de senso comum de que Freire estaria intrinsecamente relacionado ao campo da Educação de Jovens e Adultos, da alfabetização ou de movimentos sociais e educação não formal, do total de textos analisados, apenas 13 referem-se especificamente à Educação de Jovens e Adultos ou Educação ao longo da vida, 7 reportam-se a questões como movimentos sociais, cidadania ou educação não formal, e apenas 1 foca em processos de alfabetização.

Os demais trabalhos estão inseridos em processos pedagógicos que abrangem todos os níveis da educação, transitando entre estudos da infância, ensino fundamental, ensino médio e ensino superior. No âmbito do ensino superior, encontram-se 3 estudos no campo da educação em saúde e 9 na formação de professores. A partir dá, enfatiza-se a existência de ampla pulverização por áreas de conhecimento.

Verifica-se a prevalência da presença de Freire em estudos relacionados a áreas como a Filosofia, a Filosofia da Educação e o campo das políticas educacionais, além de que também se apoiam nos princípios e conceitos freirianos estudos em Tecnologias da Informação e Comunicação, Avaliação Educacional, Ensino de Ciências, Educação Matemática, Arte Educação, Literacia Crítica e de Mídia, Educação Empresarial, Violência Escolar, representações corporais e um forte impacto em textos que tratam de fundamentos das Ciências da Educação, seja na discussão de modelos educacionais ou currículo e gestão (escolar e de sala de aula). 


\section{Conceitos freirianos abordados}

$\mathrm{Na}$ análise, também se questionou quais os conceitos desenvolvidos por Freire então tomados como "lentes teóricas" para a compreensão de áreas tão diversas? Entende-se que há diferenciações importantes entre conceitos claramente construídos e delimitados por Paulo Freire, tais como "conscientização" ou "educação bancária", e elementos como "inéditos viáveis" e relações com "amorosidade/afetividade" que se apresentam no conjunto de sua obra de maneira "pulverizada". Entretanto, apenas para efeito de observação e procurando compreender a forma como diferentes autores se apropriam dos referenciais freirianos, articula-se esse conjunto de conceitos e ideias que aparece destacado nas fundamentações conceituais dos artigos analisados (Gráfico 3).

Gráfico 3 - Conceitos freirianos evidenciados nos artigos

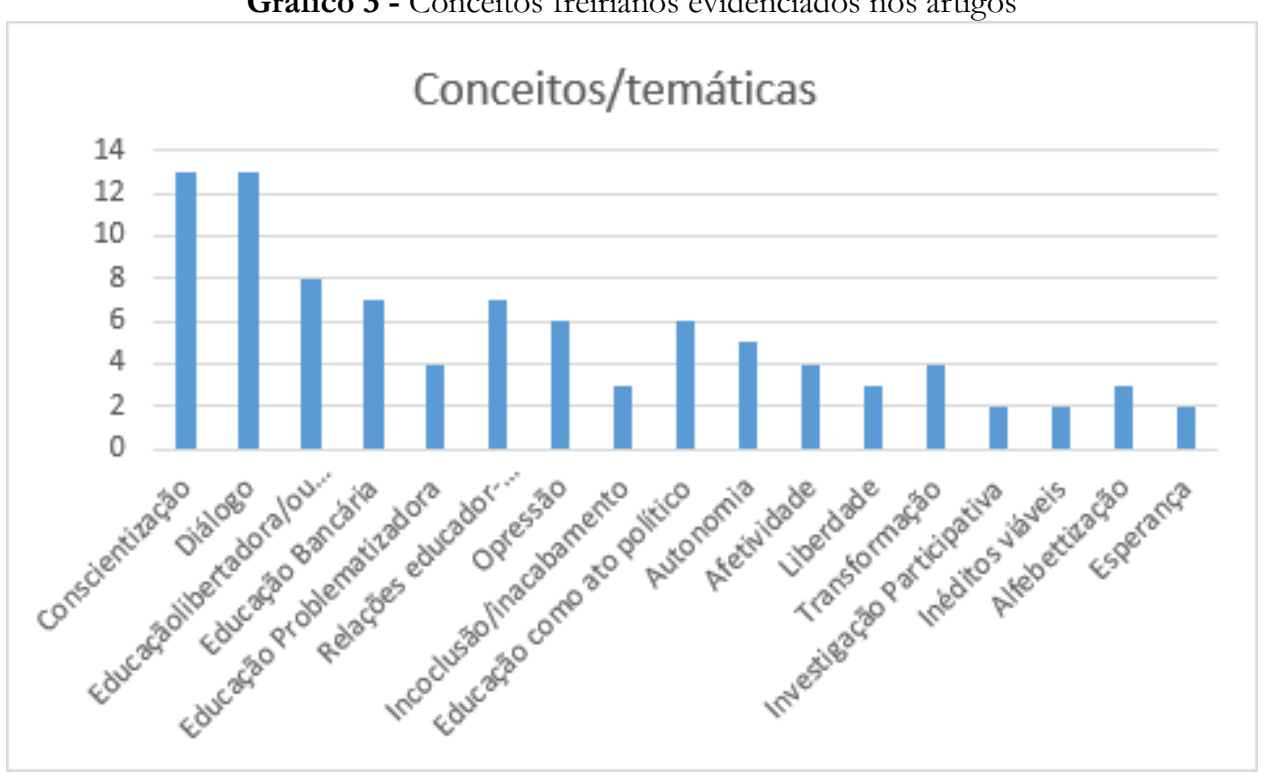

Fonte: Banco de dados da pesquisa. Elaboração das autoras.

Muitos dos conceitos desenvolvidos por Paulo Freire e que são demarcadores de sua produção teórica, entende-se, constituem-se como basilares na arquitetônica do pensamento freiriano, dos quais se destacam conscientização; diálogo; educação libertadora; educação problematizadora e/ on emancipatória; educação bancária; relações educador-educando e educação-sociedade; educação como ato político (não neutralidade); opressão e inconclusão/inacabamento. Trata-se de conceitos que se apresentam em destaque ao lado de palavras que podem ser percebidas em seu contexto de significação mais ampla, mas que em muitos momentos são trazidas à reflexão indicando serem consideradas no sentido dado por Paulo Freire. Entre essas palavras, destacam-se autonomia; liberdade; afetividade/amorosidade; experiência; indignação e esperança.

Dois outros elementos que pareceram especialmente destacados nos conceitos freirianos abordados nos textos referem-se às suas relações com a concepção de cultura. Dessa forma, entre as várias conceituações possíveis de cultura, assume-se aqui a de Chartier (2013b, p. 261), considerada como a articulação das "produções simbólicas e experiências subtraídas das emergências do cotidiano com as linguagens, os rituais e os comportamentos graças aos quais uma comunidade vive e pensa sua relação com o mundo, com os outros ou consigo mesma".

Um aspecto evidenciado por muitos autores revela-se no fato de que Freire salienta questões como a valorização das diferenças culturais, a proposição da elaboração de sínteses culturais e a articulação que se estabelece com base na palavra como elemento basilar gerador da cultura traduzida nas noções de "palavramundo" e em todas as decorrências de uma metodologia 
de alfabetização que sobrepõe à leitura da palavra, a antecedente "leitura de mundo".

Textos mais recentes, como os de Geraldi (2019) ou de Barbosa e Ferreira (2019), trazem à baila dois conceitos de Freire não tão constantemente debatidos: as noções de "inéditos viáveis" e de "investigação participativa". Conforme destacam Paro, Ventura e Silva (2020, p. 4), ao tratar dos "inéditos viáveis", "Paulo Freire não se preocupou em dar ares de conceito ao termo, (mas) as condições de emergência dos inéditos viáveis são destacadas em sua obra".

No tocante à noção de investigação participativa, embora presente nas obras do autor desde os anos de 1970, no bojo das discussões relativas ao "domínio político do conhecimento pelas elites” (DIAS; GAMA, 2014, p. 151), são menos frequentemente encontradas no campo educativo.

Ainda nessa perspectiva de abordagens contemporâneas, construindo apropriações e sentidos próprios, nem sempre pautados em temas já desenvolvidos por Freire, mas em reconfigurações das obras do autor em diversos contextos temporais e culturais, encontram-se Pesce, Bunzen Júnior e Galasso (2018) trazendo em uma discussão relativa às Tecnologias da Informação e Comunicação a noção de "empoderamento freiriano", para o qual não foram encontrados outros respaldos teóricos ou conceituais.

Freire, em diferentes momentos de sua trajetória, em textos e entrevistas, sinalizou não ter a intenção de ver seu pensamento mecanicamente reproduzido, mas mantinha a expectativa de que suas ideias fossem apropriadas e reformuladas por outros, adequados a diversas realidades e necessidades. Para a compreensão desses processos de apropriação do pensamento freiriano, reporta-se aqui aos sentidos dados por Bourdieu (1996), que considera o processo de leituras próprias mediante interpretações realizadas individualmente por sujeitos envolvidos em seu campo cultural.

\section{Repercussões do pensamento freiriano na formação de professores e interlocuções com a área}

Um dos elementos assumidos como destaque na demonstração da importância do pensamento de Paulo Freire no campo da formação de professores refere-se ao apresentado por Gonçalves e Tomás (2019), que em um estudo ouviram 115 estudantes estagiários que cursavam mestrados profissionalizantes em Portugal continental. Com o objetivo de identificar os marcos teóricos que orientavam as práticas desses estudantes no âmbito dos estágios que estavam realizando, as autoras identificaram nas subáreas da Pedagogia e da Psicologia a referência a apenas três autores não portugueses categorizados como "clássicos": Piaget, Vygotsky e Freire. Nas palavras de Gonçalves e Tomás (2019, p. 36), "Em boa verdade, são estes mesmos autores que conferem algum do peso que é atribuído à Psicologia e à Pedagogia". As perguntas levantadas no referido estudo não induziam personagens e os autores foram citados espontaneamente. No estudo integral, além dos três autores lembrados pelos participantes da pesquisa, houve referências também ao português Sérgio Niza.

No que se refere à interlocução com outros autores ou vertentes teóricas, as referências feitas a Paulo Freire colocam seus conceitos em diálogo com as produções de um farto volume de autores de todos os cantos do mundo. De maneira geral, Paulo Freire é contextualizado como um dos pensadores que desenvolveram seu modelo educacional no conjunto das pedagogias críticas e que se posiciona no intuito da transformação da sociedade, pensada pela perspectiva das "utopias" e de "inéditos viáveis". Em Amorim et al. (2011), em texto produzido por autores portugueses tratando de um projeto que pretende enfrentar questões concernentes às relações entre educação de adultos e trabalho, Freire é indicado como um autor que revela o Zeitgeist da atualidade, ou seja, 
um autor cuja obra identifica o espírito de uma época, ou o espírito de seu tempo.

\section{Produções referenciadas}

$\mathrm{Na}$ análise dos processos de circulação de textos, Chartier (2013a) destaca a ideia de "uma não hierarquização dos modos de circulação" chamando a atenção para o fato de que a materialidade do suporte destes - "o livro, seus detalhes gráficos, os avertissements au lecteur, as dedicace etc. - deve ser integrados ao estudo do texto, sob pena de certo platonismo ou certa idealização do texto abstrato original" (Chartier, 2013b, p. 244). Não é intenção aqui isolar o texto de suas bases de apresentação, mas para os efeitos deste estudo, embora se destaquem as sucessivas edições nos mais diversos países, adota-se tal perspectiva no intuito de ressaltar a representatividade do autor em variados contextos, entendendo que em estudos posteriores esse aspecto da análise do suporte material das edições possa ser extremamente relevante.

Das produções referenciadas de Paulo Freire destacam-se a nominada Opus Magnum, na perspectiva de Lima (2019), e Pedagogia do oprimido. Dos 97 textos analisados, 39 deles referem-se a esse livro. Importante destacar que, de todas as edições dessa obra referendadas, encontram-se três delas produzidas em Porto, Portugal, pela editora Afrontamento, nos anos de 1972 e 1975 (a de maior circulação), e em 2018 tem-se o registro de uma edição comemorativa aos cinquenta anos da obra. Além dessas, há um conjunto de edições novaiorquinas, datando de 1995, 2000 e 2005.

No que se refere a edições brasileiras, as obras publicadas pela editora Paz e Terra são citadas em sucessivas tiragens que atravessaram o último quartel do século XX e as primeiras duas décadas do século XXI. Não se pode deixar de considerar que aqui se trata de edições trazidas à comercialização em um país como o Brasil, cujo imaginário do senso comum indica ser um país caracterizado por uma "falta de leitores" e com tradição de produzir edições com volumes de impressão de exemplares considerados numericamente baixos, se considerados o índice populacional e a carência por saberes e cultura que o país apresenta.

Destacam-se ainda como obras amplamente referenciadas os textos Educação como prática de liberdade e Pedagogia da autonomia: saberes necessários à prática docente. Educação como prática de liberdade aparece citado em 11 dos trabalhos analisados, em especial nos artigos cujas ênfases estão postas em bases filosóficas e sociológicas e em interlocução com autores de grande destaque na produção educacional, em edições brasileiras dos anos de 1967 a 1983.

Novamente, observando-se a produção de edições em outros países, deparou-se com uma edição uruguaia de 1969 e outra inglesa, de 1974, revelando quanto, já naquele período, o trabalho de Paulo Freire tinha significativa capilarização.

Um detalhe que se encontra entre as referências é a existência do livro Uma educaşão para a liberdade, publicado na cidade do Porto pela editora Textos Marginais e que em 1974 estava em sua terceira edição. Supõe-se tratar-se do mesmo texto de Educação como prática de liberdade, mas não foi possível confirmação, por não ter sido possível encontrar publicação dessa edição que possibilitasse a comparação.

O texto Pedagogia da autonomia, referenciado em 23 dos trabalhos, é em sua totalidade de edições brasileiras, em sua maior parte (17) de edições dos anos de 1996 e 1997, mas encontrandose também referências a edições bastante recentes.

Em presenças mais pontuais, encontram-se referências a quase todas as principais obras de Paulo Freire, tais como Pedagogia da esperança; Política e educação: conscientização; Ação cultural para a liberdade; Educaşão e mudança; Educação na cidade; Cartas à Cristina, Extensão ou comunicação; Pedagogia da 
indignação; Cartas pedagógicas e outros escritos; $A$ importância do ato de ler: em três artigos que se completam e Pedagogia da tolerância.

A exemplo do que ocorre com o texto Uma educaşão para a liberdade, publicado em uma editora da cidade do Porto, Portugal, alguns outros livros em edições portuguesas aparecem nos textos analisados. Entre eles A mensagem de Paulo Freire: teoria e prática da libertação, editado em 1977, na cidade do Porto, pela editora Nova Crítica, e Educaşão política e conscientizą̧̧ão, de 1975, editado em Lisboa pela editora Sá da Costa, um indicativo da forte penetração que o pensamento de Paulo Freire tem no Portugal pós-revolucionário.

Identificou-se nesses processos o papel ativo de atores sociais no sentido apresentado por Bourdieu (1991; 1996), que atribuem significados e atuam ativamente na transformação do equilíbrio de forças em seu campo de produção cultural.

A esses somam-se vários outros textos publicados em diferentes países no formato de livros, mas também referenciação a discursos e entrevistas de Freire, esses em sua maioria disponibilizados em acervos digitais de acesso livre. No conjunto das obras obtidas em suporte digital, uma fonte relevante de consulta para os autores é o acervo disponibilizado no Instituto Paulo Freire, tanto o sediado em Portugal como no Brasil, o que assegura que os pesquisadores fiquem menos expostos a falsificações, risco alertado por Chartier (2013a) na consideração sobre a ampliação do acesso à textualidade digital.

\section{Paulo Freire como instaurador de discursos}

Referindo sobre Freire como instaurador de discursos, um fato que chama bastante atenção é a presença de artigos referindo-se a conceitos centrais de Paulo Freire, que citam no interior dos textos seu nome, mas sem necessariamente se reportar a um ou outro texto específico nas referências bibliográficas, indicando uma perspectiva de centralidade e articulação de seu pensamento como autor reconhecido e portador de uma identidade própria e mundialmente consolidada. Isso ocorre em pelo menos 10 dos textos analisados.

No mesmo sentido da regularidade temporal na presença de citações e referenciações a Freire ao longo dos treze anos analisados, esse entendimento da solidez do pensamento freiriano é ainda reafirmado se se considerar a regularidade das edições que vão desde as primeiras obras, do final dos anos 1960, até as mais recentes reedições.

Finalmente, são extremamente numerosas as traduções referenciadas nos mais diversos idiomas e países, salientando de forma ainda mais contundente o alcance que as ideias desenvolvidas por Freire e seu reconhecimento como instaurador de pensamento no campo das pedagogias críticas é sólido.

\section{Considerações finais}

Refletir sobre os processos de formação de professores e de produção de conhecimentos no campo da educação como um dos elementos relevantes à efetivação de processos educacionais formais e informais com índices de qualidade que permitam aos indivíduos obter o seu pleno desenvolvimento, exercer a cidadania e preparar-se para o mundo do trabalho, como preconizado na lei de diretrizes e bases da educação brasileira, é tema que parece permanentemente significativo e que leva a reflexão se tem havido uma produção de conhecimentos pedagógicos cuja relevância seja tal que justifique a circulação em outros contextos culturais. 
Nesse sentido, o estudo que aqui se apresenta tendo por objetivo identificar a presença do pensamento educacional brasileiro na formação de professores em Portugal e em publicações em periódicos acadêmico-científicos da área da educação naquele país apontou que, entre os pensadores brasileiros cujas produções teóricas circulam com maior intensidade, destaca-se o trabalho de Paulo Freire.

Paulo Freire, autor que é associado à Educação de Jovens e Adultos, em especial pelo desenvolvimento de uma metodologia de alfabetização que foi disseminada, adaptada e replicada em vários países do mundo desde os anos de 1960, aparece nos dados identificados no processo de pesquisa como referencial em unidades curriculares de cursos de formação de professores, mas também como base teórica de análise em estudos e pesquisas dos mais diversos níveis e modalidades de ensino, além de sua presença em trabalhos cujo foco se situa nos mais variados campos culturais e disciplinares.

Nos limites que propostos a analisar, composto de materiais e documentos disponíveis para acesso em meios digitais, obteve-se um mapeamento que indica que a circulação do pensamento educacional brasileiro, por meio de um de seus mais relevantes autores, é amplo, atual e com forte potencial de expansão no tempo e em diferentes espaços. Nos estudos analisados, que listamos no Anexo A do texto, observa-se que a circulação desse pensamento ocorre por intermédio de autores de diferentes países e continentes, em muitos casos em nações com resultados positivos nos testes de larga escala de avaliação dos sistemas educacionais.

Além desse aspecto mais objetivo, foi possível observar que na circulação das ideias pedagógicas, filosóficas e sociológicas de Freire, nas publicações de autores estrangeiros de reconhecida relevância e vinculados a instituições de ensino superior, também com alto desempenho e valorização em âmbito mundial, constata-se a fragilidade de discursos que, irresponsável e inconsequentemente, buscam desqualificar sua produção.

Compreende-se que os resultados aqui apresentados são limitados e restritos no tempo e no espaço de sua elaboração, mas espera-se que promova uma expansão de conhecimento no intuito de aproximar um número maior de pesquisadores e profissionais da educação da obra desse que tem sido dos mais reconhecidos educadores do Brasil. Entende-se ainda que este estudo possa ser também ampliado na busca de aprofundar conhecimentos sobre a circulação e a apropriação das ideias de Paulo Freire não apenas em outros contextos culturais, mas também em contexto brasileiro, em virtude de dúvidas quanto à efetiva compreensão e valorização de sua obra.

Anexo A - Lista de trabalhos que compuseram o estudo deste artigo

ABDI, A. A.; SHULTZ, L. Citizenship and youth social engagement in Canada: learning challenges and possibilities. Sisyphus: Journal of Education, Lisboa, v. 1, n. 2, p. 54-74, 2003. DOI: https://doi.org/10.25749/sis.3629

AFONSO, A. J. Estado, Mercado, comunidade e avaliação: Esboço para uma (re)articulação crítica. Educação, Sociedade \& Culturas, Porto, n. 52, p. 133-155, 2017.

ALCOFORADO, L.; VIEIRA, M. C. A educação de pessoas adultas como promotora da igualdade de oportunidades entre homens e mulheres. Algumas reflexões. Revista Portuguesa de Pedagogia, Coimbra, n. 41-3, p. 173-193, 2007. DOI: https://doi.org/10.14195/1647-8614 41 $\underline{38}$

ALMEIDA, L. M. P. Competências: um caminho educativo para novos desafios. Revista Portuguesa de Pedagogia, Coimbra, ano 41-3, p. 245-262, 2007. 
AMORIM, J. P.; AZEVEDO, J.; IMAGINÁRIO, L.; COIMBRA, J. L. O sentimento de Sísifo: experiências de não emprego subjetivadas por adultos sobrequalificados. Revista Portuguesa de Investigação Educacional, Porto, n. 10, p. 233-251, 2011. DOI: https://doi.org/10.34632/investigacaoeducacional.2011.3339

ANDREOTTI, V. O. Critical and transnational literacies in international development and global citizenship education. Sisyphus: Journal of Education, Lisboa, v. 2, n. 3, p. 32-50, 2014. DOI: https://doi.org/10.25749/sis.6544

ARAÚJO, A. F.; ARAÚJO, J. M. Utopia e educação. Revista Portuguesa de Pedagogia, Coimbra, ano 40-1, p. 95-117, 2006. DOI: https://doi.org/10.14195/1647-8614 40-1 4

ARAÚJO, A. F. Can we talk of educative modernity without metaphors? The example of the agricultural metaphor in the pedagogical work of Célestin Freinet. Sisyphus: Journal of Education, Lisboa, v. 4, n. 1, p. 173-197, 2016. DOI: $\underline{\text { https://doi.org/10.25749/sis.10463 }}$

ARAÚJO, J. J. C. N.; SOEIRO, E. M. O Estado avaliador e a violência simbólica do sistema estadual de avaliação de aprendizagem do Acre (SEAPE) - Brasil. Revista Portuguesa de Investigação $\begin{array}{llllll}\text { Educacional, } & \text { Porto, } & \text { n. } & 14, & \text { p. } & 137-151,\end{array}$ https://doi.org/10.34632/investigacaoeducacional.2014.3403

AZEVEDO, J. Construir uma escola democrática e justa: o arco maior e a pedagogia da misericórdia. Revista Portuguesa de Investigação Educacional, Porto, n. 16, p. 201-230, 2016. DOI: https://doi.org/10.34632/investigacaoeducacional.2016.3427

AZEVEDO, M. C. Valores culminantes: educação para a morte / Educação para a vida. Revista Portuguesa de Pedagogia, Coimbra, ano 40-2, p. 159-183, 2006. DOI: https://doi.org/10.14195/1647-8614 40-2 5

BAHIA, S. Especificidades da formação de professores de artes e de humanidades. Sísifo Revista de Ciências da Educação, Lisboa, n. 8, p. 101-112, 2009.

BALDI, E. M. B. A docência no ensino superior: perspectivas e imagens. Revista Portuguesa de Pedagogia, Coimbra, ano 44-1, p. 169-193, 2010. DOI: http://dx.doi.org/10.14195/1647$\underline{8614 \quad 44-1 \quad 7}$

BARBOSA, I. O fascismo ainda mora cá dentro? O teatro-jornal e o discurso da austeridade. Educação, Sociedade \& Culturas, Porto, n. 49, p. 31-71, 2016.

BRAGGIO, A.; FIUZA, A. O exílio dos professores brasileiros em Portugal e a documentação da DOPS-PR. Revista Portuguesa de Educação, Braga, v. 32, n. 1, p. 16-34, 2019. DOI: https://doi.org/10.21814/rpe.14274

BRAYNER, F. Homens e mulheres de "palavra\&quot: diálogo e educação popular. Revista Portuguesa de Educação, Braga, v. 22, n. 1, p. 207-224, 2018. DOI: https://doi.org/10.21814/rpe.13958

CAETANO, P; FREIRE, I. Multiple voices to the development of a critical and responsible citizenship. Sisyphus: Journal of Education, Lisboa, v. 2, n. 3, p. 100-119, 2014. DOI: https://doi.org/10.25749/sis. 6547

CANÁRIO, R. Recensão da obra "Paulo Freire e o nacionalismo desenvolvimentista", de Vanilda Paiva [2000 (reedição)]. São Paulo: Graal. Sísifo - Revista de Ciências da Educação, Lisboa, v. 2, p. 83-86, 2007. 
CARAMUJO, M. S.; FERREIRA, J. A. Educação e formação de adultos e bem-estar: estudo longitudinal. Revista Portuguesa de Pedagogia, Coimbra, ano 40-3, p. 207-222, 2007.

CARVALHO, R. M. P.; MACHADO, J. Governação da escola e contratos de autonomia. Revista Portuguesa de Investigação Educacional, Porto, n. 10, p. 5-24, 2011. DOI: http://dx.doi.org/10.34632/investigacaoeducacional.2011.3329

CASTRO, J. F. P. Lifelong education on Portuguese emigrants and their acculturation. Sisyphus: Journal of Education, Lisboa, v. 6, n. 1, p. 97-119, 2018. DOI: https://doi.org/10.25749/sis.13798

CAVACO, C. Reconhecimento, validação e certificação de competências: complexidade e novas actividades profissionais. Sísifo - Revista de Ciências da Educação, Lisboa, n. 2, p. 21-34, 2007.

CHARLOT, B. O trabalho docente, a análise da actividade e o papel dos sujeitos. Sísifo - Revista de Ciências da Educação, Lisboa, n. 9, p. 119-128, 2009.

CHARLOT, B. A pesquisa educacional entre conhecimentos, políticas e práticas: especificidades e desafios de uma área de saber. Revista Brasileira de Educação, Rio de Janeiro, v. 11, n. 31, p. 718, 2006.

CLOUGH, N.; TARR, J.; STACHYRA, K.; ADDESSI, A. R.; MALISZEWSKA, K. Exploring teacher competences for relational health in schools. Educação, Sociedade \& Culturas, Porto, n. 50, p. 15-32, 2017.

COELHO, D. P.; CARAMELO, J.; MENEZES, I. Educação para o desenvolvimento na era global: possibilidades de uma leitura pós-colonial. Educação, Sociedade \& Culturas, Porto, n. 53, p. 97 119, 2017.

CORREIA, A. M. Da gestão da sala de aula à aprendizagem: o uso da fenomenografia na análise das conceções de gestão de sala de aula dos formandos. Revista Portuguesa de Investigação Educacional, Porto, n. 19, p. 257-280, 2019. DOI: https://doi.org/10.34632/investigacaoeducacional.2019.5300

CORREIA, J. A. Conferência de abertura do $1^{\circ}$ Congresso das Licenciaturas em Ciências da Educação. Educação, Sociedade \& Culturas, Porto, n. 24, p. 193-208, 2007.

CORTESÃO, I.; AMORIM, E.; MENEZES, I. "O coro torna-nos pessoas diferentes e melhores!...": visões de crianças do $1^{\circ}$ ciclo sobre a experiência de um projeto de música comunitária. Educação, Sociedade \& Culturas, Porto, n. 54, p. 153-174, 2019.

CORTESÃO, L. Guliver entre gigantes: na tensão entre estrutura e agência, que significados para a educação? Educação, Sociedade \& Culturas, Porto, n. 39, p. 159-181, 2013.

COUTINHO, C. P.; LISBÔA, E. S. Sociedade da informação, do conhecimento e da aprendizagem: desafios para a educação no século XXI. Revista de Educação, [s. l.], v. XVIII, n. 1, p. 5-22, 2011.

ESTEBAN, M. T. Provinha Brasil: desempenho escolar e discursos normativos sobre a infância. Sísifo - Revista de Ciências da Educação, Lisboa, n. 9, p. 47-56, 2009.

ESTÊVÃO, C. V. Direitos humanos, justiça e educação. Educação, Sociedade \& Culturas, Porto, n. 25, p. 43-81, 2007.

FARTES, V. B.; GONÇALVES, C. B. Formação de professores para a educação profissional de 
jovens e adultos no Brasil: novas relações com o saber, novo campo de trabalho na educação. Educação, Sociedade \& Culturas, n. 29, p. 109-124, 2009.

FISCHER, M. C. B.; FRANZOI, N. L. Formação humana e educação profissional: diálogos possíveis. Educação, Sociedade \& Culturas, Porto, n. 29, p. 35-51, 2009.

FERNÁNDEZ, T. O grande louco: o olhar insubordinado de Simón Rodríguez. Educação, Sociedade \& Culturas, Porto, n. 39, p. 55-75, 2013.

FLOWERS, E. Drawing bodies/drawing students: making up relationships in curriculum reform. Sisyphus: Journal of Education, Lisboa, v. 3, n. 1, p. 96-135, 2015. DOI: https://doi.org/10.25749/sis. 7722

FONSECA, E. N. Contributos para a formação do educador à luz do mandato moral da escola. Revista Portuguesa de Pedagogia, Coimbra, ano 46-2, p. 9-30, 2012. DOI: http://dx.doi.org/10.14195/1647-8614 46-2 1

FRAGA, N.; TEODORO, A. A reconfiguração da gestão da coisa pública face à emergência de processos participativos centrados no cidadão: o caso do orçamento participativo de Palmela. Educação, Sociedade \& Culturas, Porto, n 49, p. 111-130, 2016.

FREIRE, I.; BAHIA, S.; ESTRELA, M. T.; AMARAL, A. A dimensão emocional da docência: contributo para a formação de professores. Revista Portuguesa de Pedagogia, Coimbra, ano 46-2, p. 151-171, 2012. DOI: https://doi.org/10.14195/1647-8614_46-2 8

GADOTTI, M. Educar adultos hoje na perspectiva de Paulo Freire. Revista Portuguesa de Pedagogia, Coimbra, ano 35-1, p. 31-40, 2011.

GUENDELMAN, C. K. Alteridade e diálogo como elementos constituintes do fazer educativo um olhar para a perspectiva dialógica. Revista Portuguesa de Pedagogia, Coimbra, ano 52-2, p. 5-18, 2018. DOI: https://doi.org/10.14195/1647-8614_52-2_1

HAYASHI, M. C.; HAYASHI, C. R.; MARTINEZ, C. M. Estudos sobre jovens e juventude: diferentes percursos refletidos na produção científica brasileira. Educação, Sociedade \& Culturas, Porto, n. 27, p. 131-154, 2008.

JOBERT, G. Os formadores de adultos e a ideologia da mudança social. Revista Portuguesa de Pedagogia, Coimbra, ano 41-3, p. 33-42, 2007.

JUNG, H. S.; NOGARO, A.; SUDBRACK, E. M. C. O mundo líquido que desorienta os mapas: aspectos da pós-modernidade em Boaventura de Sousa Santos e Zygmunt Bauman para resgatar a utopia na educação. Educação, Sociedade \& Culturas, Porto, n. 49, p. 151-168, 2016.

KONING, M. Evening Knowledge: Paulo Freire e a luz transbordando a taça do Graal. Revista Educação Sociedade e Culturas, Porto, n. 54, p. 117-129, 2019.

LEITE, Á. P. Paulo Freire e a arte educação: considerações sobre a estética freiriana e a arte na educação/formação. Revista Educação Sociedade e Culturas, Porto, n. 54, p. 85-103, 2019.

LEMOS, F. C. S.; REIS JÚNIOR, L. P. Subjetividades em dívida: formação e sociedade de controle. Sisyphus: Journal of Education, Lisboa, v. 5, n. 1, p. 89-100, 2017.

LEMOS, S. F. C.; COSTA, S. G.; LIMA, R. C. P. Representações sociais: aplicabilidade nos estudos sobre a Educação de Jovens e Adultos. Educação, Sociedade \& Culturas, Porto, n. 39, p. 43-61, 
2013.

LINHARES, E. F.; REIS, P. Exposição interativa sobre geoengenharia climática: capacitação de futuros professores para a ação sociopolítica. Sisyphus: Journal of Education, Lisboa, v. 5, n. 3, p. 85-106, 2017.

LIRA, A. Escola no século XXI: o passado engajado no presente. Sisyphus: Journal of Education, Lisboa, v. 7, n. 3, p. 74-91, 2019. DOI: https://doi.org/10.25749/sis.18225

LOPES, A. M. L.; FERREIRA, E. M. S. A figura do diretor - (des)continuidades narrativas de líderes e liderados em contexto escolar. Revista Portuguesa de Investigação Educacional, Porto, n. 13, p. 137-154, 2013. DOI: https://doi.org/10.34632/investigacaoeducacional.2013.3392

LOPES, D. M. C.; VAZ-REBELO, M. P. P.; PESSOA, M. T. R. O ensino superior na atualidade e os desafios da aprendizagem: teorizações e prática docente. Revista Portuguesa de Pedagogia, Coimbra, ano 44-1, p. 143-167, 2010. DOI: http://dx.doi.org/10.14195/1647-8614 44-1 6

LUZ, R. H. A escola e a alfabetização no Brasil: um olhar histórico. Revista Portuguesa de Pedagogia, Coimbra, ano 43-1, p. 189-204, 2009. DOI: http://dx.doi.org/10.14195/1647$\underline{8614 \quad 43-1 \quad 10}$

MACHADO, J.; FORMOSINHO, J. Igualdade em educação, uniformidade escolar e desafios da Diferenciação. Revista Portuguesa de Investigação Educacional, Porto, n. 11, p. 29-43, 2012. DOI: https://doi.org/10.34632/investigacaoeducacional.2012.3344

MAGALHÃES, A. M. The creation of the EHEA, "learning outcomes" and the transformation of educational categories in higher education. Educação, Sociedade \& Culturas, Porto, n. 31, p. 37-50, 2010.

MAGALHÃES, A. M.; STOER, S. R. A narrativa das narrativas: um estudo das narrativas educacionais dos investigadores/docentes da FPCE-UP. Educação, Sociedade \& Culturas, Porto, n. 24, p. 135-154, 2007.

MARTINS, F. J. A pedagogia da terra: os sujeitos do campo e do ensino superior. Educação, Sociedade \& Culturas, Porto, n. 36, p. 103-119, 2012.

MENA-LORENZO, J. A.; MENA-LORENZO, J. L. El método de formación en la actividad profesional productiva. Revista Portuguesa de Pedagogia, Coimbra, ano 53-1, p. 81-96, 2019. DOI: https://doi.org/10.14195/1647-8614 53-1_5

MESQUITA, E.; FORMOSINHO, J.; MACHADO, J. Supervisão da prática pedagógica e colegialidade docente. A perspectiva dos candidatos a professores. Revista Portuguesa de Investigação Educacional, Porto, n. 12, p. 59-77, 2012. DOI: https://doi.org/10.34632/investigacaoeducacional.2012.3375

MONTEIRO, H. Investigação, transformação e "palavramundo": novos e velhos desafios éticometodológicos. Educação, Sociedade \& Culturas, Porto, n. 54, p. 65-84, 2019.

MOURA, M. O.; LOPES, A. R. L. V.; CEDRO, W. L. A formação inicial de professores que ensinam matemática: a experiência do Clube de Matemática. Revista de Educação, [s. l.], v. XVI, n. 2, p. 123-137, 2008.

NEVES, M. O. A construção da identidade de professores do campo: um novo passo rumo à valorização da cultura camponesa. Revista Portuguesa de Pedagogia, Coimbra, ano 46-2, p. 173 - 
188, 2012. DOI: https://doi.org/10.14195/1647-8614_46-2_9

NOGUEIRA, A.; GONÇALVES, M.; COSTA, J. A. A intervenção da inspeção na avaliação externa das escolas: um estudo com base nas perceções de diretores de escolas. Revista Portuguesa de Educação, Braga, v. 32, n. 2, p. 171-187, 2019. DOI: https://doi.org/10.21814/rpe.14812

NORONHA, D. P.; VITÓRIA, P. R. Cinema, memória e educação em direitos humanos. O uso de filmes em sala de aula e a disputa pela narrativa sobre a ditadura civil-militar brasileira. Educação, Sociedade \& Culturas, Porto, n. 54, p. 131-152, 2019.

OLIVEIRA, M. J.; PÉREZ, A.; PEREIRA, I.; SANTOS, A. Citizenship and human rights education: evaluation of an intervention project through the arts. Educação, Sociedade \& Culturas, Porto, n. 49, p. 135-156, 2016.

PAIVA, V.; PAIVA, E. Violência em escolas do Rio de Janeiro nos últimos 15 anos. Sísifo - Revista de Ciências da Educação, Lisboa, n. 10, p. 101-110, 2009.

PALHARES, J. A. Os sítios de educação e socialização juvenis: experiências e representações num contexto não-escolar. Educação, Sociedade \& Culturas, Porto, n. 27, p. 109-130, 2008.

PEDRO, A. Razão filosófica e razão educativa: a filosofia da educação como uma filosofia aplicada.

Revista Portuguesa de Pedagogia, Coimbra, ano 40-1, p. 185-196, 2006. DOI: http://dx.doi.org/10.14195/1647-8614 40-1_8

PEREIRA, I. Uma teoria materialista em educação, inspirada por Paulo Freire, em França. Educação Sociedade \& Culturas, Porto, n. 54, p. 47-64, 2019.

PINTO, A. B. M.; DELGADO, P. Currículo por competências e sucesso escolar no ensino profissional: uma relação por construir. Revista Portuguesa de Investigação Educacional, Porto, n. 14, p. 209-227, 2014. DOI: https://doi.org/10.34632/investigacaoeducacional.2014.3405

REIA-BAPTISTA, V. Conceitos e processos formativos de pedagogia e literacia dos Media. Revista Portuguesa de Pedagogia, Coimbra, ano 42-2, p. 65-77, 2008. DOI: http://dx.doi.org/10.14195/1647-8614 42-2 4

RIBEIRO, M. M. O(s) trabalho (s) educativo(s) no reconhecimento, validação e certificação de competências: contributos para a transformação dos ofícios de ensinar e de aprender em educação de adultos. Educação, Sociedade \& Culturas, Porto, n. 31, p. 123-142, 2010.

RODRÍGUEZ, J. M. M. Pedagogía de los espacios. La comprensión del espacio en el proceso de construcción de las identidades. Revista Portuguesa de Pedagogia, Coimbra, ano 43-1, p. 5-25, 2009. DOI: https://doi.org/10.14195/1647-8614_43-1_1

RODRÍGUEZ BORREGO, M. A.; BORONAT MUNDINA, J.; FREIRE, I. Metodologias colaborativas, educação na e para a responsabilidade na formação em enfermagem. Sísifo - Revista de Ciências da Educação, Lisboa, v. 7, p. 63-74, 2008.

ROMÃO, J. Razões oprimidas. Revista Portuguesa de Educação, Braga, v. 23, n. 2, p. 7-34, 2018. DOI: https://doi.org/10.21814/rpe.13985

ROTHENBURGER, C. Towards a territorialised professional identity: the case of teaching staff in rural schools in France, Spain, Chile and Uruguay. Sisyphus: Journal of Education, Lisboa, v. 3, n. 2, p. 78-97, 2015. DOI: https://doi.org/10.25749/sis.7887 
SAMPAIO, M.; LEITE, C. A avaliação externa das escolas e os TEIP na sua relação com a justiça social. Educação, Sociedade \& Culturas, Porto, n. 47, p. 115-136, 2016.

SANTOS, H.; SALDANHA, L.; PINTO, M.; FERREIRA, P. D. "Videojogos do oprimido": contributos para o desenvolvimento de um framework freiriano. Educação, Sociedade \& Culturas, Porto, n. 54, p. 175-195, 2019.

SILVA, J. P. R. Turma 2.0. O Facebook como instrumento de criação de uma comunidade aprendente: reflesão sobre uma experiência de utilização do Facebook com os alunos e os pais de uma turma de uma escola TEIP. Revista Portuguesa de Investigação Educacional, Porto, n. 11, p. 169-182, 2012. DOI: https://doi.org/10.34632/investigacaoeducacional.2012.3352

SIMONNEAUX, L.; SIMONNEAUX, J.; CANCIAN, N. Socially acute agri-environmental questions and changes in society: educational transition for societal transition via the agroecological transition. Sisyphus: Journal of Education, Lisboa, v. 5, n. 2, p. 40-60, 2017. DOI: https://doi.org/10.25749/sis.11840

SOPELSA, O. O ensinar e o aprender no ensino Fundamental: um movimento interativo com a pesquisa. Sísifo - Revista de Ciências da Educação, Lisboa, n. 4, p. 137-146, 2007.

SOUSA, C. A. M.; SOARES, L. H.; MARIZ, R. S. Utopias e distopias em um cenário prospectivo entre a educação e as tecnologias digitais de informação e comunicação. Sisyphus: Journal of Education, Lisboa, v. 7, n. 3, p. 10-29, 2019. DOI: https://doi.org/10.25749/sis.18212

SWANSON, D. M. Neoliberalism, education and citizenship rights of unemployed youth in postapartheid South Africa. Sisyphus: Journal of Education, Lisboa, v. 1, n. 2, p. 194-212, 2013. DOI: https://doi.org/10.25749/sis.3635

STOER, S. R.; ARAÚJO, H. C. Basic human and social rights and the democratic school on the European (semi)periphery. Educação, Sociedade \& Culturas, Porto, n. 54, p. 217-231, 2019.

TEODORO, A. C. Um sistema com três equações e três incógnitas: uma experiência pedagógica relacionada com a docência de uma unidade curricular de $2^{\circ}$ ciclo a três formações distintas. Educação, Sociedade \& Culturas, Porto, n. 46, p. 127-143, 2015.

TERESHCHENKO, A. Highlighting place and space in studies of youth citizenship identities. Educação, Sociedade \& Culturas, Porto, n. 30, p. 145-160, 2010.

TOCHON, F. V. Deep education: assigning a moral role to academic work. Educação, Sociedade \& Culturas, Porto, n. 33, p. 17-35, 2011.

TORRES, R. T. Uma intervenção social pedagógica: reflexões sobre a educação como forma de reabilitação para a reinserção social. Educação, Sociedade \& Culturas, Porto, n. 33, p. 141-157, 2011.

VASCONCELOS, I. C. O. Violência escolar: morte da escola ou fênix? Sisyphus: Journal of Education, Lisboa, v. 7, n. 3, p. 45-73, 2019. DOI: https://doi.org/10.25749/sis.18224

VASCONCELOS, T. Supervisão como um "TEAR": estratégias emergentes de "andaimação" definidas por supervisoras e supervisionadas. Revista de Educação, [s. l.], v. XV, n. 2, p. 5-21, 2007.

VIEIRA, F. Em contracorrente: o valor da indagação da pedagogia na universidade. Educação, Sociedade \& Culturas, Porto, n. 2, p. 107-126, 2009. 
VIEIRA, V. L.; LEITE, C.; CERVATO-MANCUSO, A. M. Formação superior em saúde e demandas educacionais atuais: o exemplo da graduação em nutrição. Educação, Sociedade \& Culturas, Porto, n. 39, p. 25-42, 2013.

ZAGALO-CARDOSO, J. A.; SILVA, A. S. O homem planetário e os seus desafios para a educação. Revista Portuguesa de Pedagogia, Coimbra, ano 41, n. 1, p. 77-86, 2007. DOI: https://doi.org/10.14195/1647-8614 41-1 5

\section{Referências}

BARBOSA, A. M. A imagem no ensino da arte. São Paulo: Perspectiva, 1991.

BARBOSA, I.; FERREIRA, F. I. Investigação participativa e compromisso com a transformação do mundo: diálogos com Paulo Freire. Educação, Sociedade \& Culturas, Porto, n. 54, p. $197-$ $215,2019$.

BOTO, C. Um credo pedagógico na democracia escolar: algum traçado do pensamento de John Dewey. Educação, Porto Alegre, v. 3, n. 60, p. 599-619, 2006.

BOURDIEU, P. Le champ littéraire. Actes de la Recherche en Sciences Sociales, Lyon, n. 89, p. 4-46, 1991.

BOURDIEU, P. Razões práticas: sobre a teoria da ação. Campinas: Papirus, 1996.

CANDAU, V. Direitos humanos, educação e interculturalidade: as tensões entre igualdade e diferença. Revista Brasileira de Educação, Rio de Janeiro, v. 13, n. 37, p. 45-56, 2008. DOI: https://doi.org/10.1590/S1413-24782008000100005

CHARTIER, R. A ordem dos livros: leitores, autores e bibliotecas na Europa entre os séculos XIV e XVII. Brasília, DF: Editora UnB, 1994.

CHARTIER, R. Uma trajetória intelectual: livros, leituras, literaturas. In: ROCHA, J. C. C. Roger Chartier, a força das representações: história e ficção. Chapecó: Argos Editora, 2013a. p. 21-53.

CHARTIER, R. Aula inaugural do Collège de France. In: ROCHA, J. C. C. Roger Chartier, a força das representações: história e ficção. Chapecó: Argos Editora, 2013b. p. 249-285.

DIAS, S.; GAMA, A. Investigação participativa baseada na comunidade em saúde pública: potencialidades e desafios. Revista Panamericana de Salud Publica, Washington, v. 35, n. 2, p. 150-154, 2014.

FREIRE, P. Extensão ou comunicação. Rio de Janeiro: Paz e Terra, 1971.

FREIRE, P. Pedagogia do oprimido. Porto: Afrontamento, 1972.

FREIRE, P. Pedagogia do oprimido. Porto: Afrontamento, 1975a.

FREIRE, P. Educação como prática de liberdade. Rio de Janeiro: Paz e Terra, 1975b.

FREIRE, P. Cartas a Cristina. São Paulo: Paz e Terra, 1994.

FREIRE, P. Pedagogia da autonomia: saberes necessários à prática educativa. São Paulo: Paz e Terra, 1996. 
FREIRE, P. Pedagogia da autonomia. São Paulo: Paz e Terra, 2000a.

FREIRE, P. A importância do ato de ler. São Paulo: Cortez Editora, 2000b.

GABARDO, C. V. A formação de professores em perspectivas internacionais. Estudo comparado entre modelos europeus e brasileiro. Educar em Revista, Curitiba, n. 29, p. 279-280, 2007. DOI: https://doi.org/10.1590/S0104-40602007000100019

GATTI, B. A. Formação de professores no Brasil: características e problemas. Educação \& Sociedade, Campinas, v. 31, n. 113, p. 1.355-1.379, 2010. DOI: https://doi.org/10.1590/S0101$\underline{73302010000400016}$

GERALDI, J. W. Sala de aula: espaço de "inéditos viáveis". Educação, Sociedade \& Culturas, Porto, n. 54, p. 31-45, 2019.

GONÇALVES, C.; TOMÁS, C. Textos e contextos: a relação entre teoria e prática na PES pela voz de futuros/as educadores/as e professores/as. Revista Portuguesa de Pedagogia, Coimbra, ano 53-1, p. 21-38, 2019. DOI: https://doi.org/10.14195/1647-8614 53-1 2

GONDRA, J. G. (org.). História, infância e escolarização. Rio de Janeiro: 7 Letras, 2002.

LARAIA, R. A cultura, um conceito antropológico. Rio de Janeiro: Zahar Editores, 1986.

LIMA, L. C. A pedagogia do oprimido como fonte para a crítica ao pedagogismo opressor. Educação, Sociedade \& Culturas, Porto, n. 54, p. 11-29, 2019.

MACHADO, M. M.; BARROS, R. Aspectos da construção histórica da identidade da Educação de Jovens e Adultos no Brasil e em Portugal: enfoque na agenda política e suas práticas discursivas. Cadernos de História da Educação, Uberlândia, v. 19, n. 1, p. 91-109, 2020. DOI: https://doi.org/10.14393/che-v19n1-2020-8

MAINARDES, J. Abordagem do ciclo de políticas: uma contribuição para a análise de políticas sociais e educacionais. Educação \& Sociedade, Campinas, v. 27, n. 94, p. 47-69, 2006. DOI: https://doi.org/10.1590/S0101-73302006000100003

MEKSENAS, P. Pesquisa social e ação pedagógica. Conceitos, métodos e prática. São Paulo: Edições Loyola, 2002.

MOGARRO, M. J. Bibliotecas particulares e saberes pedagógicos: circulação e apropriação de modelos culturais. In: PINTASSILGO, J.; FREITAS, M. C.; MOGARRO, M. J.; CARVALHO, M. M. C. (org.). História da escola em Portugal e no Brasil: circulação e apropriação de modelos culturais. Lisboa: Colibri, 2006. p. 233-257.

OLIVEIRA, M. K. Vygotsky: aprendizado e desenvolvimento - um processo sócio-histórico. São Paulo: Editora Scipione, 1997.

PARO, C. A.; VENTURA, M.; SILVA, N. E. K. Paulo Freire e o inédito viável: esperança, utopia e transformação na saúde. Trabalho, Educação e Saúde, Rio de Janeiro, v. 18, n. 1, e0022757, 2020. DOI: https://doi.org/10.1590/1981-7746-sol00227

PESCE, L.; BUNZEN JÚNIOR, C.; GALASSO, R. Tecnologias e empoderamento: análise da implementação do programa um computador por aluno no estado de São Paulo, Brasil. Sisyphus: Journal of Education, Lisboa, v. 6, n. 3, p. 8-29, 2018. DOI: https://doi.org/10.25749/sis.15068 
PEZZONI, C. Como Portugal elevou sua educação às melhores do mundo: pouco dinheiro, muito empenho. BBC News, São Paulo, 21 out. 2018. Disponível em: https://www.bbc.com/portuguese/internacional-45806314. Acesso em: 6 jan. 2021.

PIMENTA, S. G. (ed.). Didática e formação de professores: percursos e perspectiva no Brasil e em Portugal. São Paulo: Cortez, 2006.

PINTASSILGO, J.; OLIVEIRA, H. A formação inicial de professores em Portugal: reflexões em torno do atual modelo. Revista Contemporânea de Educação, Rio de Janeiro, v. 8, n. 15, p. $26-$ 43, jan./jul. 2013. DOI: https://doi.org/10.20500/rce.v8i15.1684

SASSAKI, A. H.; PIETRA, G. A. C.; MENEZES FILHO, N. A.; KOMATSU, B. K. Por que o Brasil vai mal no PISA? Uma análise dos determinantes do desempenho no exame. Policy Paper, São Paulo, n. 31, p. 1-24, 2018.

SAVIANI, D. Educação brasileira: estrutura e sistema. 8. ed. Campinas: Autores Associados, 2010.

SILVA, T. T. Teorias do currículo: uma introdução crítica. Porto: Porto Editora, 2005.

VIDAL, D. G. (org.). Grupos escolares (1893-1971). Campinas: Mercado de Letras, 2006.

Recebido em 20/08/2021

Versão corrigida recebida em 29/01/2021

Aceito em 01/02/2021

Publicado online em 15/02/2021 